\title{
GLOMERULAR DYNAMICS IN THE NORMAL HUMAN KIDNEY 1
}

\author{
BY HOMER W. SMITH, HERBERT CHASIS, WILLIAM GOLDRING, \\ AND HILMERT A. RANGES
}

\begin{abstract}
(From the Departments of Physiology and Medicine, New York University College of Medicine, and the Third (New York University) Medical Division of Bellevue Hospital, New York City)
\end{abstract}

(Received for publication May 13, 1940)

One of the most interesting facts about the renal circulation is that during marked changes in renal blood flow (adrenalin ischemia and pyrogenic hyperemia) the rate of glomerular filtration typically remains unchanged. This fact has been attributed to the circumstance that the changes in renal blood flow are mediated primarily by changes in the tonus of the efferent arterioles; consequently, any increase or decrease in blood flow is accompanied by a reciprocal change in glomerular filtration pressure, with the result that the filtration rate remains unchanged (3).

Beyond the fact that this emphasis upon the efferent arteriole is to some extent contrary to the importance which has hitherto, chiefly for anatomical reasons, been attached to the afferent vessel, this description of the glomerular circulation presents several interesting implications. It assumes that the rate of glomerular filtration is determined solely by glomerular pressure factors, exclusive of any limitation imposed by the permeability of the glomerular membranes. There logically issues from this assumption the question whether or not filtration pressure equilibrium is normally reached in the glomerulus. The answer to this question is of practical importance in two respects. If filtration equilibrium is reached in the glomerular circulation, then this fact must set the upper limit to the hydrostatic pressure available to propel blood through the efferent arterioles and the postglomerular circulation. And in the face of a demonstration of filtration equilibrium in the normal kidney, a decrease in filtration rate in renal disease cannot logically be attributed to reduced permeability of the glomerular capillaries, in contradistinction to a decrease in filtration pressure or in total filtering

1 This investigation has been supported in part by aid from the William Gibbs Memorial Prize Fund, granted especially for the study of renal hyperemia, and in part by the Commonwealth Fund. surface, without evidence that glomerular permeability is actually reduced.

These and other considerations lead us to a further analysis of this problem. It has recently been shown that the inulin and diodrast clearances in different subjects are closely correlated with differences in the tubular excretory mass (diodrast $T m$ ), it being presumed that the last term varies with the total quantity of renal parenchyma (8). It is advantageous to utilize this correlation in examining the relations which exist in various subjects between the inulin and diodrast clearances; i.e., to make this comparison in terms of the ratios, $C_{I N} / T m_{D}$ and $C_{D} / T m_{D}$ (where $C_{I N}$ and $C_{D}$ are the inulin and diodrast clearances, respectively, and $T m_{D}$ is diodrast $T m$ ). Such an analysis is, in the first approximation; equivalent to comparing the filtration rate and renal plasma flow of various subjects on the basis of their actual renal weights.

Furthermore, we now have in our records numerous data, not available when the previous paper was published, on the diodrast and inulin clearances in normal subjects under various conditions of renal blood flow. These data may be divided in to three categories: (1) observations made during standard conditions (quoted from Tables I and II of Goldring, et al. (8), which we will designate as "basal," with the reservations concerning the use of this word stated by the above authors; (2) observations made during the reduced renal blood flow induced by adrenalin, neosynephrin and marked apprehension, and here referred to as "ischemia;" and (3) observations made during the increased renal blood flow ("hyperemia") induced by the intravenous administration of typhoid vaccine or pyrogenic inulin. The action of adrenalin and typhoid vaccine on the renal blood flow has been discussed by Chasis, et al. (3) and the action of pyrogenic inulin and of apprehension by Smith (26). The observations utilized here include those re- 


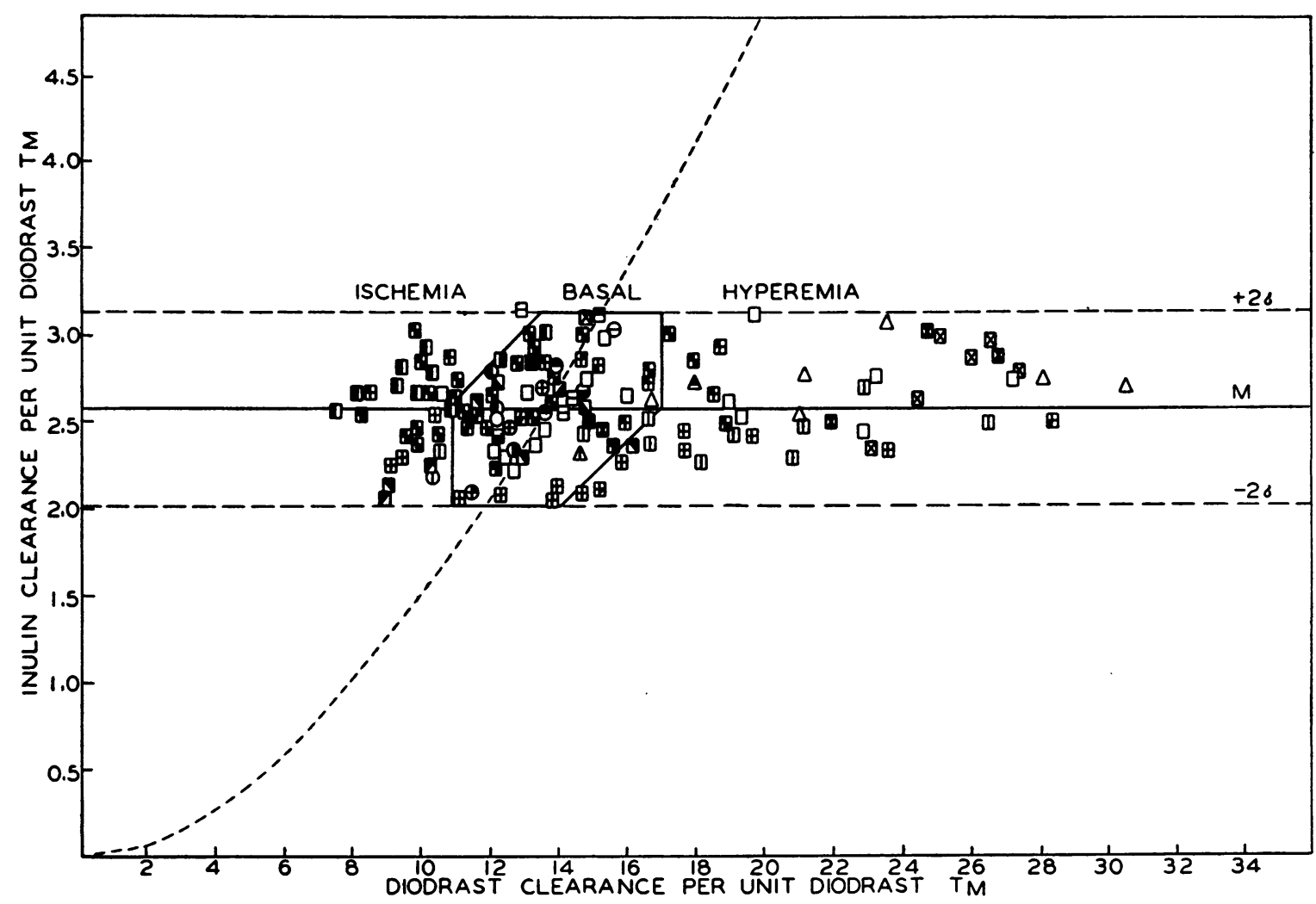

Fig. 1. The Filtration Rate (Inulin Clearance) in Normal Subjects in Relation to the Renal Plasma Flow (Diodrast Clearance) During Basal Conditions, Ischemia Induced by Adrenalin, Etc., and Hyperemia Induced by Typhoid Vaccine or Pyrogenic Inulin

On the assumption that diodrast $T m$, which is a measure of the total tubular excretory tissue in the kidney, is closely proportional to the total renal weight, a comparison of the inulin and diodrast clearances in terms of the respective value of diodrast $T m$ in various subjects is equivalent to comparing the filtration rate and renal blood flow per unit weight of kidney.

Each datum represents the average of two or more clearance periods, each subject furnishing several datum on each examination under ischemia or hyperemia.

The solid horizontal line shows the predicted relation if the changes in renal blood flow are attributable solely to changes in efferent resistance; the rising dotted line shows the predicted relation if the changes in blood flow are attributable solely to changes in afferent resistance, the alternate resistance in each case remaining constant at the status of the mean of the basal observations, 95 per cent of which are included in the hexagon.

corded in the above papers and similar observations, made by the same methods, which need not be presented in detail.

The above data are presented graphically in Figures 1 and 2. Each datum referred to the "basal" group is the average of three or more consecutive clearance periods taken on any one day, each subject being recorded as of ten as he or she was examined. Each datum referable to "ischemia" or "hyperemia" is the average of at least two successive clearance periods obtained during reduced or increased renal blood flow, each subject thus contributing several data from each occasion on which ischemia or hyperemia was induced.

Figure 1 presents the ratio $C_{I N} / T m_{D}$ (the filtration rate per unit diodrast $T m$ ) in relation to $C_{D} / T m_{D}$ (the effective plasma flow per unit diodrast $T m$ ). Instead of analyzing this miscellany of data on their intrinsic relations, we have arbitrarily chosen to appraise them in terms of our previously published standard figures. Goldring, et al. (8) have reported that in 35 men and women the average value of $C_{I N} / T m_{D}=2.56$ \pm 0.28 cc. per minute; for purposes of comparison we have marked this mean (solid line) 


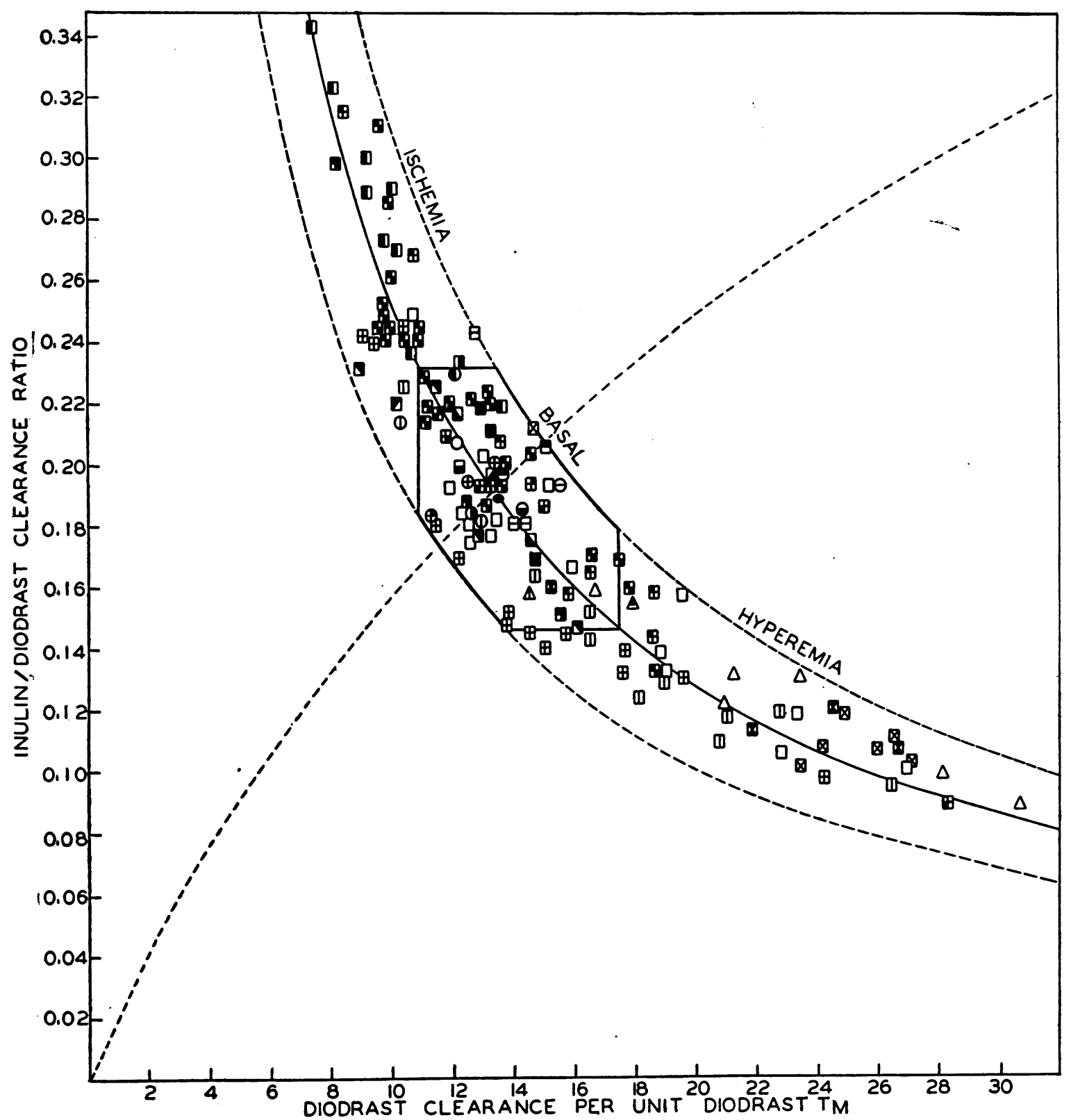

Fig. 2. The Data of Figure 1 Arranged to Show the Per Cent of Water filtered Out of the Plasma (Filtration Fraction), as Given by the Inulin/Diodrast Clearance Ratio, at Various Rates OF BLOOd Flow

As in Figure 1, the solid line refers to changes in efferent resistance, the dotted line to the changes in afferent resistance.

with twice its standard deviation (dashed lines) on the ordinates of Figure 1. It is to be noted especially that the mean value quoted from Goldring, et al., includes only observations made under what we have here called "basal" conditions, and that in its calculation each subject enters only once, thus contributing to the mean only his or her average behavior; while the data of Figure 1 comprise the unaveraged and hence more widely distributed behavior of all individuals, not only under basal conditions, but also during ischemia and hyperemia. 
It is evident from this comparison that the miscellany of unaveraged values of $C_{I N} / T m_{D}$ obtained at all renal blood flows is still adequately contained within the statistical parameters of the more restricted "basal" data. It may be said, then, that the filtration rate per unit diodrast $T m$ in various normal subjects retains the same mean value during ischemia and hyperemia induced by the measures specifically stated above as it has in the basal condition. (It is not implied that this constancy will obtain if ischemia or hyperemia are induced by measures other than those stated.)

The view that this constancy of the filtration rate is to be attributed to the physiological circumstance that changes in renal blood flow are mediated through changes in the tonus of the efferent, rather than the afferent, glomerular arterioles requires that the effective glomerular filtration pressure must vary inversely as the renal blood flow. In the following discussion we shall inquire both whether the observed facts are open to any other interpretation, and if not, whether they are consonant with the application of simple hemodynamic principles to the glomerular circulation.

\section{THE NOTION OF CONDITIONED FILTRATION}

Although contrary to the accepted principles applicable to glomerular filtration in particular, and capillary permeability in general, it might be argued that the constancy of the rate of glomerular filtration at varying rates of renal blood flow is attributable to special properties of the filtering bed whereby the separation of capsular urine from plasma is independent of glomerular pressure. In considering such an hypothesis, it must be noted that in mammals we have no specific knowledge of the rate of passage of water per se across the glomerular membranes, our information being restricted to inulin and other solutes. It might be supposed, then, that the glomerular membranes so condition the passage of inulin that the quantity of this substance which enters Bowman's capsule per unit time is both constant and independent of glomerular pressure. That such conditioning does not apply to inulin molecules per se is controverted by the facts, first, that inulin is present in the capsular fluid of frogs and necturi in the same concentration as it is present in plasma water (10); and second, that under controlled conditions in individual animals, inulin is excreted in widely varying total quantities, but always in proportion to its plasma concentration $(7,11,14$, $16,19,20,23,25)$; such wide latitude in absolute rate of excretion, combined with close proportionality to plasma concentration, is evidence against the conditioned passage of this molecule by the glomerular membranes.

It could still be argued, however, that the conditioning factors in the glomerular membranes are such as to permit the passage into Bowman's capsule per unit time of a constant volume of the solvent, water, with its inulin and all other contained solutes, the volume so passed being relatively independent of glomerular pressure. (Such a system is roughly imitated in a "slow" filter, i.e., one in which a high resistance so restrains the movement of fluid that hydrostatic pressure is subordinate to other forces in determining the rate of passage.)

Against this interpretation the following evidence can be adduced. Any membrane conditioning the passage of water independently of pressure can do so only under circumstances where the gross movement of water is highly restricted, and where specific intermolecular forces (surface tension, adsorption, diffusion, solubility, etc.) are the determinants of translocation. Under these circumstances the passage of various molecular species are, with no known exception, differentially conditioned, at least to the extent that the more diffusible species move more rapidly than the less diffusible ones. The now abundant evidence on the passage of solutes through the glomeruli reveals no such differential permeability. The work of Richards and his collaborators $(17,18)$ has shown that all analyzable, diffusible solutes in the plasma are passed in unchanged proportions into the capsular space of the Amphibia, the most noteworthy instance being the simultaneous passage of water and inulin molecules, as referred to above. An equally strong argument can be based upon the identity of the inulin and creatinine clearances in the dog, frog and rabbit $(7,11,19,20,22,39)$, which identity is preserved under all conditions 
of filtration so far examined in normal animals. So far as man is concerned, more immediate evidence is available in the identity of the creatinine and inulin clearances in phlorizinized subjects (21), and the identity of the xylose and inulin clearances during hyperglycemia in dog and man (Shannon and Fisher, 24, and unpublished observations by these authors). Lastly, there are now available observations that show that the clearances of mannitol, sorbitol, and sorbitan in normal men and women, and in women with pre-eclampsia, are identical with the simultaneous inulin clearance (28). Since the molecular species enumerated above differ markedly in diffusion velocities and in physical properties $(2,31)$, this evidence argues against the belief that the constancy of the filtration rate is due to the circumstance that the movement of water itself is restrained to a constant volume per unit time by the high resistance of the filter.

If the above evidence is adequate to exclude the conditioned passage of inulin specifically, and the conditioned passage of water and solutes generally, then the only alternative is to recognize that water with its contained solutes moves through the glomerular membranes in consequence of differences in hydrostatic pressure, not restrained to a significant degree by viscous or frictional forces. This view is, of course, the classical concept of glomerular filtration.

\section{FILTRATION PRESSURE EQUILIBRIUM}

We pass, then, to the consideration of the pressure relations within the glomeruli. It is recognized, first, that the passage of plasma water and diffusible solutes into Bowman's capsule occurs only in consequence of the fact that the hydrostatic pressure within the glomerular capillaries $\left(P_{G}\right)$ exceeds the sum of the oncotic pressure $\left(P_{o}\right)$ plus the capsular pressure $\left(P_{C}\right)$. (By capsular pressure we designate the pressure existing in Bowman's capsule; this pressure will be approximately equal to the intrarenal or interstitial pressure and must, so long as urine is flowing, be sufficient to overcome the resistance offered by the tubules and collecting ducts to the passage of urine into the renal pelvis where, for purposes of discussion, the pressure may be taken to be zero.)
Secondly, in conformity with generally accepted relations in the mesenteric and systemic capillaries (12), we conceive that the filtration process is a reversible one and that if $P_{G}$ falls below $P_{c}+P_{o}$, fluid will be reabsorbed from Bowman's capsule into the glomerular capillaries. Hence we write:

$$
\underset{\text { reabsorption }}{\stackrel{\text { flitration }}{\longrightarrow}} P_{c}+P_{o} .
$$

After a certain interval of exposure, an interval which will be determined by the permeability of the glomerular membranes, the opposing pressures tending to effect filtration and reabsorption, respectively, will become equal to each other and the process of filtration will stop. This state we designate as filtration pressure equilibrium, or more briefly, filtration equilibrium; under these conditions, the hydrostatic pressure in the glomerular capillaries $\left(P_{G^{\prime}}\right)$ is equal to the sum of the equilibrium oncotic pressure $\left(P_{O^{\prime}}\right)$ plus the capsular pressure $\left(P_{C}\right)$.

$$
P_{\sigma^{\prime}}=P_{c}+P_{o^{\prime}} \text {. }
$$

This concept of filtration equilibrium will be made clearer by reference to Figure 3.

We will return later to the question of whether or not the duration of exposure of the plasma in the glomerular capillaries is sufficient to permit filtration equilibrium to be reached. But to facilitate discussion we will assume in the following that such is the actual case.

\section{FILTRATION PRESSURE}

On the question of what pressure is available in the glomerulus to effect filtration, Winton's $(37,38)$ studies on the isolated dog kidney indicate that the mean glomerular pressure in this preparation can vary from 30 to 90 per cent, and averages about 60 per cent, of the systemic pressure. If we take the more conservative figure of $\mathbf{5 0}$ per cent for the mean glomerular pressure, and if we take the mean systemic pressure as $90 \mathrm{~mm}$. of $\mathrm{Hg}$, the mean glomerular pressure $\left(P_{G}\right)$ will average $45 \mathrm{~mm}$. As stated in equation (2), at equilibrium this value must be equal to the oncotic pressure plus the capsular pressure. Accepting the inulin/diodrast clearance ratio as identical with the per cent of plasma 


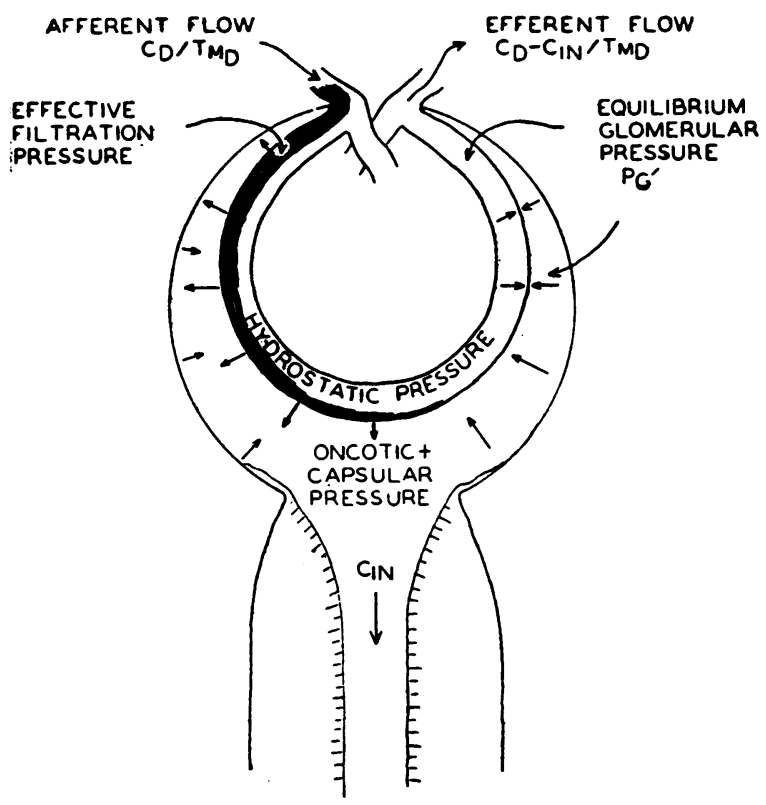

Fig. 3. Filtration Equilibrium in Glomerulus

It is supposed that in the arterial end of the glomerular capillary water and solutes move from capillary into capsule because the hydrostatic pressure $\left(P_{G}\right)$ exceeds the sum of the oncotic pressure $\left(P_{O}\right)$ and the capsular pressure $\left(P_{C}\right)$. The pressure gradient between capillary and capsule, indicated by the shaded area, is dissipated in effecting the process of filtration and moving the blood forward in the capillary, so that by the time the blood reaches the efferent arteriole $P_{\sigma^{\prime}}=P_{C}+P_{O^{\prime}}$, and the process of filtration stops. This condition is designated as filtration equilibrium. Insofar as the hydrostatic pressure suffers a further decrement in the distal portion of the capillary after filtration equilibrium has once been reached, capsular fluid will be reabsorbed, as in the systemic capillaries, leaving $\boldsymbol{P}_{\boldsymbol{G}^{\prime}}=\boldsymbol{P}_{C}+\boldsymbol{P}_{\boldsymbol{O}^{\prime}}$.

Since $\boldsymbol{P}_{0}$, may be calculated from the initial oncotic pressure of the plasma $\left(P_{0}\right)$ and the filtration fraction, we may, by taking $\boldsymbol{P}_{\boldsymbol{C}}$ at an arbitrary and constant value, calculate $\boldsymbol{P}_{\boldsymbol{G}}$, for various values of the renal plasma flow (diodrast clearance) and filtration rate (inulin clearance).

water filtered through the glomeruli, or what we have called the filtration fraction $(F F)$, we may calculate the equilibrium oncotic pressure $\left(P_{O^{\prime}}\right)$ as

$$
P_{O^{\prime}}=P_{o}\left(1+\frac{F F}{1.0-F F}\right),
$$

where $P_{0}$ is the initial oncotic pressure.

$F F$ averages 18.9 per cent in men and 19.8 in women; taking the round figure of 20 per cent, and taking $P_{o}$ as $24 \mathrm{~mm}$. (36), at filtration equilibrium the plasma proteins will have been concentrated 1.25 times, and $P_{o}$ raised from 24 to $30 \mathrm{~mm}$. $\mathrm{Hg}$. Under these conditions the capsular pressure $\left(P_{C}=P_{G^{\prime}}-P_{O^{\prime}}\right)$ will be equal to $45-30$ or $15 \mathrm{~mm}$. There is, at present, no way of determining the capsular pressure in man, but Winton (38) reports the interstitial pressure of the excised dog kidney to be typically below $15 \mathrm{~mm} . \mathrm{Hg}$, and it may be inferred that the normal value in man, if not less than this, is probably not more than $25 \mathrm{~mm}$.

Accepting tentatively the figure of $15 \mathrm{~mm}$. for the capsular pressure, and assuming that during constriction of the efferent arterioles $P_{G^{\prime}}$ rises to 70 per cent of the mean systemic pressure, or to $63 \mathrm{~mm}$., then filtration will continue until $P_{o}$ rises from 24 to $48 \mathrm{~mm}$. $(63-15 \mathrm{~mm}$.), i.e., until the plasma proteins have been doubled in concentration by the filtration of 50 per cent of the plasma water. A filtration fraction of $\mathbf{5 0}$ per cent lies well above the highest normal filtration fraction on record ( 33 per cent), so that it appears that ample pressure can be made available by efferent constriction to account for both the mean and the maximal filtration fraction observed.

Since at equilibrium, $P_{\sigma^{\prime}}=P_{O^{\prime}}+P_{C}$, the last two terms set the maximal hydrostatic pressure available to propel blood through the efferent arteriole and the postglomerular circulation. Continuing with the above example, if 50 per cent of the plasma water is filtered, the hydrostatic pressure will be $48+15=63 \mathrm{~mm}$.; while if only 10 per cent of the plasma water is filtered, the hydrostatic pressure will be $26.6+15=41.6$ $\mathrm{mm}$. Both during ischemia and hyperemia, therefore, there will be sufficient hydrostatic pressure at filtration equilibrium to maintain the postglomerular circulation. If filtration equilibrium is not reached, $P_{G^{\prime}}$ will be greater than $P_{O^{\prime}}+P_{C}$ and a still more effective pressure head will be available for the postglomerular circulation.

\section{VELOCITY OF FILTRATION}

Whether the permeability of the glomerular membranes is such as to permit filtration equilibrium to be reached before the blood leaves the glomeruli is not established. Richards and Walker (18) report that the glomerulus of the frog may filter water at the rate of 4 cubic $\mathrm{mm}$. per hour. The effective filtration pressure in the frog may be taken as 2.5 to $5 \mathrm{~mm}$. $\mathrm{Hg}(6,9,31)$. 
With $2,465,600$ glomeruli in two human kidneys (14), a comparable rate of filtration would yield 32 to $64 \mathrm{cc}$. per $\mathrm{mm}$. $\mathrm{Hg}$ effective filtration pressure and, since the initial glomerular pressure probably exceeds $P_{C}+P_{0}$ by several millimeters, the above figure exceeds the requirements of the largest observed filtration rate.

The total capillary surface area of a typical human glomerulus, according to Book (1), is 0.3813 sq.mm.; in the two kidneys the total filtering surface would then be slightly under $\mathbf{1 . 0}$ sq.m. Taking the average renal plasma flow as $688 \mathrm{cc}$. per minute and the average filtration rate as $130 \mathrm{cc}$. per minute, it follows that some $12 \mathrm{cc}$. of plasma are passed per second over a filter which has a total area of about 1.0 square meter, giving a sheet of plasma virtually $0.012 \mathrm{~mm}$. deep. (The filter itself is scarcely over $0.001 \mathrm{~mm}$. in thickness.) The premise of filtration equilibrium requires that within one second's time and by the movement of 20 per cent of the water through the filter the pressures on both sides are equalized.

Landis (12) has calculated that an increment of $50 \mathrm{~mm} . \mathrm{H}_{2} \mathrm{O}$ increases the rate of filtration through the mesenteric capillaries of the frog by 0.03 cubic micra per square micron per second. With a total capillary area of 1.0 meter, $50 \mathrm{~mm}$. of $\mathrm{H}_{2} \mathrm{O}$, or $3.68 \mathrm{~mm}$. $\mathrm{Hg}$, would filter $4.74 \mathrm{cc}$. of water per minute. This figure is considerably below both the filtration rate recorded by Richards and Walker and the requirements of the human glomerulus, but it is not of an order of magnitude to cast serious doubt upon the possible velocity of filtration in the latter.

If filtration equilibrium is not reached in the distal portion of the capillary, the glomerular membranes fall in the category of a "slow" filter as described above, and it would be expected that there would be a differential passage of those solutes which have a much higher diffusion coefficient than does inulin (2). The evidence against such differential passage, as reviewed above, argues generally in favor of equilibrium. Although the thesis is not at present amenable to experimental proof in the human kidney, we are inclined, in the light of the available evidence, to accept it as a premise in the analysis of glomerular dynamics.

If filtration equilibrium is reached at normal rates of blood flow, it will also be reached during ischemia, since greater time will be available for equilibrium to be attained. And since the maximal rate of blood flow in any one individual is but little over twice the basal, it may be assumed that filtration equilibrium will also be reached during renal hyperemia.

\section{FILTRATION FRACTION IN RELATION TO RENAL BLOOD FLOW}

In Figure 2 we have plotted the filtration fraction (calculated as the inulin/diodrast clearance ratio) against the diodrast clearance per unit diodrast $T m$, or $C_{D} / T m_{D},{ }^{2}$ and it will be seen that the filtration fraction is inversely related to the renal plasma flow-a statement which is merely a corollary of the fact (Figure 1) that the filtration rate is constant at all rates of renal plasma flow.

The inverse relationship of Figure 2 is described by the formula for a rectangular hyperbola wherein the product of the two terms, $F F$ and $C_{D} / T m_{D}$, is a constant:

Since

$$
F F \frac{C_{D}}{T m_{D}}=k
$$

$$
F F \cdot C_{D} / T m_{D}=C_{I N} / T m_{D},
$$

it follows from (4) that

$$
C_{I N} / T m_{D}=k .
$$

The value of $k$, as given by the ratio $C_{I N} / T m_{D}$ in the observed data, is $2.56 \pm 0.28$. Inserting this value in equation (4) yields the solid curve in Figure 2, while $\pm 2 \sigma$ yields the dashed lines.

\section{CHANGES IN GLOMERULAR PRESSURE AND BLOOD FLOW ATTRIBUTABLE TO CHANGES IN EFFERENT ARTERIOLAR TONE}

In order to interpret the data of Figures 1 and 2 , we pass to the consideration of what relation-

2 It does not materially alter this analysis if the diodrast extraction ratio in the blood going to active nephrons is less than 1.0 by some constant amount or if a small fraction of the urinary diodrast is derived from the red blood cells $(5,33,34)$. Appropriate correction for this circumstance can be made by taking the true plasma flow as $C_{D} / E_{D}$, where $E_{D}$ is the arteriovenous diodrast extraction ratio in this blood. Substitution of this term in equation (4) will lead to proportional changes in all subsequent calculations but will not change the general dynamic relations. The maximal correction as indicated by the available data on $E_{D}$ in the dog is about 10 per cent. 
ships may be expected to obtain between $C_{I N} / T m_{D}, C_{D} / T m_{D}$ and $F F$ if changes in renal blood flow are the result solely of changes in resistance offered by the efferent arterioles, the resistance offered by the afferent arterioles and the postglomerular circulation and the mean systemic pressure remaining constant.

In any simplified quantitative treatment, it is unnecessary to consider the whole blood diodrast clearance, since the plasma diodrast clearance serves equally well to describe volume flow changes so long as the relative volume of cells in the blood remains constant. We may, in general, speak of changes in blood flow, although actually all data and equations given here refer to plasma flow. We may also neglect changes in viscosity associated with the separation of glomerular filtrate; that such changes do occur is clear, but it is doubtful if they are normally of such a magnitude as to be important.

The following propositions are germane to the quantitative description of glomerular pressure:

(a) The glomerular blood flow is represented, not by the afferent (or total) flow entering the glomerulus, but by the efferent flow leaving the glomerulus; assuming that there is no significant aglomerular blood supply to the tubules, the efferent flow is given by the difference between the total flow, $C_{D} / T m_{D}$, and the volume of filtrate, $C_{I N} / T m_{D}$, or $C_{D} / T m_{D}-C_{I N} / T m_{D}$.

(b) The effective glomerular pressure (i.e., the pressure available to move blood between the glomeruli and the renal vein) is the difference between the hydrostatic pressure in the efferent end of the glomerular capillaries and such pressure distally as may oppose this hydrostatic pressure. Contributing to this opposing pressure is the renal venous pressure, a force so small (1 to $3 \mathrm{~mm}$. $\mathrm{Hg}$ ) that for general purposes it may be neglected. But in addition to venous pressure, a force equal to the sum of the renal interstitial pressure $\left(P_{C}\right)$ plus the oncotic pressure of the blood $\left(P_{0}\right)$ opposes the perfusion of the kidney. The way in which the latter operates will be clear if it is noted that within any semipermeable compartment immersed in water at atmospheric pressure there exists a hydrostatic pressure relative to the atmosphere equal to the osmotic (or oncotic) pressure of the non-diffusible constituents; this hydrostatic pressure must be maintained so long as water continues to exist outside the compartment, otherwise water will enter until equality between osmotic force and hydrostatic pressure is re-established. Conversely, in order to maintain water outside the compartment, the internal hydrostatic pressure must equal the oncotic pressure.

Applying the above principle to the kidney, if at any point in the capillary bed between the glomeruli and the renal vein an opportunity exists for osmotic equilibrium to be attained between the blood and the interstitial fluid, then the hydrostatic pressure of the blood in the peritubular capillaries must be at least as large as the oncotic pressure, $P_{o}$. Should the pressure be lowered at either end of the capillary, the internal hydrostatic pressure will move blood along the pressure gradient and simultaneously interstitial fluid will move into the capillary, and this process will continue until the ingress of interstitial fluid either restores the hydrostatic pressure to $P_{o}$, or until the available interstitial fluid is exhausted. Thus, so long as free interstitial fluid exists and so long as opportunity is afforded for the attainment of osmotic equilibrium between this fluid and the plasma, the hydrostatic capillary pressure cannot be less than $P_{o}$. Now in point of fact interstitial fluid is present around the peritubular capillaries throughout their length, and in view of the large expanse of these capillaries it must be assumed that osmotic equilibrium does exist along at least some portion of this capillary bed; consequently, the capillary pressure in this bed and at all points proximal to it cannot fall below $P_{o}$. (This is equivalent to saying that in consequence of the fact that water is free to move through the capillary wall, the capillary is compressed by an external force equal to the difference in vapor pressure of water on the two sides, i.e., the oncotic pressure. Once the blood moves into an impermeable vessel (vein) the hydrostatic pressure will fall below the oncotic pressure, since the ingress of water to maintain this pressure is no longer possible. The above argument will perhaps be clearer if, for such expressions as "osmotic equilibrium " or " the opportunity to attain osmotic equilibrium" there is substituted the idea of an instantaneous transfer of water to the 
end that osmotic equilibrium is invariably maintained.)

Since there also exists in the kidney an interstitial pressure $\left(P_{C}\right)$ which compresses the capillary bed externally, this pressure must be added to $P_{o}$, so that the minimal capillary pressure must be written as equal to $P_{c}+P_{o}$. Only when the perfusion pressure exceeds $P_{c}+P_{o}$ will fluid move through the peritubular capillaries into the renal vein; short of this time, any increment in perfusion pressure will serve only to move fluid out of the capillary into the interstitial space until osmotic equilibrium is attained.

The effective perfusion pressure, $P_{B}$, is then the glomerular pressure, $P_{G}$, minus the opposed pressures, $P_{c}+P_{o}$, or

$$
P_{B}=P_{G}-\left(P_{C}+P_{o}\right) \text {. }
$$

(c) Where a change in blood flow results from a change in the resistance offered by the efferent arterioles (both afferent arteriolar resistance and postglomerular resistance being held constant), the effective perfusion pressure, $P_{E}$, will according to hemodynamic principles vary inversely as the efferent blood flow, or

$$
P_{B}=k_{1} \frac{1}{C_{D} / T m_{D}-C_{I N} / T m_{D}} .
$$

Hence, from (7) and (8),

(9) $P_{G}=P_{C}+P_{O}+\frac{k_{1}}{C_{D} / T m_{D}-C_{I N} / T m_{D}}$.

The above equation affords a hemodynamic description of how the efferent blood flow will vary with changes in glomerular pressure when the variable resistance is on the efferent side of the glomeruli.

(d) But under the premise of filtration equilibrium, the glomerular pressure, $P_{G}$, as it appears in equation (9), is identical with $P_{\sigma^{\prime}}$ in equation (2); by substituting for $P_{o}$, in this equation the right-hand term of equation (3), and replacing $F F$ by $\frac{C_{I N} / T m_{D}}{C_{D} / T m_{D}}$ of equation (6), it follows that

$$
P_{G^{\prime}}=P_{C}+P_{O}+\frac{P_{O} C_{I N} / T m_{D}}{C_{D} / T m_{D}-C_{I N} / T m_{D}}
$$

Equating (9) and (10),

$$
P_{O} C_{I N} / T m_{D}=k_{1} \text {. }
$$

Since $\boldsymbol{P}_{\boldsymbol{o}}$ in any one subject is in principle a fixed value,

$$
C_{I N} / T m_{D}=\text { a constant value. }
$$

Thus it is deducible in theory that, when changes in renal blood are a result solely of changes in the resistance offered by the efferent arterioles, the rate of glomerular filtration will remain constant. This is the relationship which is demonstrated to exist in fact in the human kidney, as shown in Figure 1.

Relative to equation (11), $C_{I N} / T m_{D}$ has the experimentally determined value of 2.56 ; if $P_{o}$ is taken as $24 \mathrm{~mm}$. $\mathrm{Hg}(36), k_{1}=61.4$. The inverse relations that exist between $C_{D}$ and $F F$ (Figure 2) issue, of course, directly from the constancy of the inulin clearance.

By arbitrarily taking $P_{C}=15 \mathrm{~mm} . \mathrm{Hg}$ (vide supra), and assuming that this term remains constant at varying rates of blood flow, and by taking $P_{O}=24$ and $C_{I N} / T m_{D}$ as equal to 2.56 (as experimentally observed) $P_{G^{\prime}}$ can be calculated from equation (10) for various values of $C_{D}$. Such calculated values are shown graphically in Figure 4.

\section{MAXIMAL FILTRATION FRACTION AND EFFERENT GLOMERULAR STASIS}

Under extreme efferent constriction, $P_{c}+P_{o}$ will ultimately rise to a value equal to the mean systemic pressure, and consequently $F F$ must in theory have an upper limiting value. At a mean systemic pressure of $90 \mathrm{~mm}$. $\mathrm{Hg}, F F$ cannot exceed 68 per cent, for at this degree of protein concentration $P_{O^{\prime}}$ will be $75 \mathrm{~mm}$. which, with $P_{C}=15 \mathrm{~mm}$., will give a glomerular pressure equal to the systemic pressure, or $90 \mathrm{~mm}$. Insofar as this pressure exceeds the postglomerular pressure, blood will flow through the glomeruli with the maximal filtration fraction of 68 per cent. Further efferent constriction will then reduce this blood flow without increasing the percentage of water filtered. Actually stasis will no doubt occur before the resistance of the efferent arterioles is such as to produce a maximal filtration fraction, since the abstraction of plasma water will produce a critical increase in the apparent viscosity of the blood cells, and an increase in viscosity will serve just as well to raise 


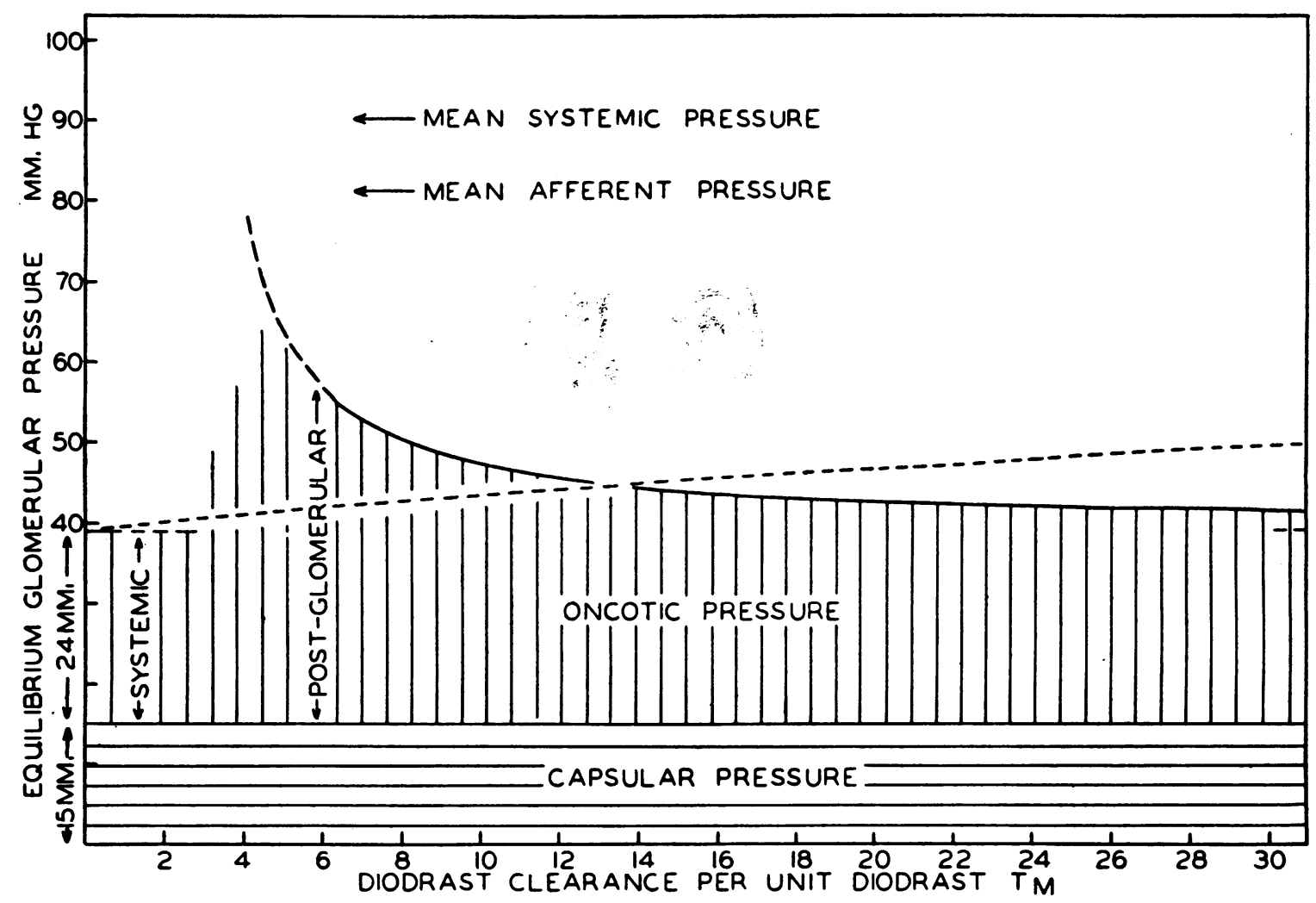

Fig. 4. Equilibrium Glomerular Pressure ( $\left.\boldsymbol{P}_{G^{\prime}}\right)$ Calculated for Efferent Control (Solid Line) and Afferent Control (Dotted Line), Assuming That the Tone of the Afferent or Efferent Arterioles, Respectively, Remain Fixed at the Normal Basal Values Corresponding to the Median of the Basal DATA IN Figure 1

$P_{G}$, to the level of the systemic pressure as an increase in efferent arteriolar resistance.

Whether glomerular stasis ever results in fact from efferent arteriolar constriction cannot be said at the present time. At the lowest rates of blood flow recorded here, neither the limit set on the filtration fraction by the available systemic pressure nor that set by increasing viscosity of blood has apparently been approached.

CHANGES IN GLOMERULAR PRESSURE AND BLOOD FLOW ATTRIBUTABLE TO CHANGES IN AFFERENT ARTERIOLAR TONE

(e) Where a change in blood flow results from a change in the resistance offered by the afferent arterioles (both efferent arteriolar resistance and postglomerular resistance being held constant), the effective perfusion pressure, $P_{E}$, will vary directly as the efferent blood flow, or

$$
P_{E}=k_{2}\left(C_{D} / T m_{D}-C_{I N} / T m_{D}\right)
$$

Since forward blood flow will not begin until $P_{G}$ exceeds $P_{C}+P_{o}$ (as shown under $(b)$ above), (14) $P_{G}=P_{C}+P_{O}+k_{2}\left(C_{D} / T m_{D}-C_{I N} / T m_{D}\right)$.

This equation affords a hemodynamic description of how the efferent blood flow will vary with changes in glomerular pressure when the variable resistance is on the afferent side of the glomeruli.

Again $P_{G}$ may be identified with the equilibrium glomerular pressure $P_{G^{\prime}}$; at any point where this value and $C_{D} / T m_{D}$ and $C_{I N} / T m_{D}$ are known, the value of $k_{2}$ may be calculated, this value representing a given fixed efferent resistance. For this purpose we select the mean blood flow under basal conditions, where $C_{D} / T m_{D}$ $=13.4, C_{I N} / T m_{D}=2.56$ and, according to equation (10), $P_{G}=44.67$. From equation (14) it follows that $k_{2}=0.521$. By the introduction of this value in equation (14) and by the rearrangement of this equation, we may calculate the 
values of $P_{G^{\prime}}, C_{I N} / T m_{D}$, and $F F$ corresponding to various values of $C_{D} ; P_{E}$ is first obtained for selected values of $C_{D} / T m_{D}-C_{I N} / T m_{D}$ by multiplying the latter by $k_{2}$; adding $P_{E}$ to $P_{O}$ yields $P_{O^{\prime}}$, which when added to $P_{C}$ yields $P_{G^{\prime}} ;$ while

$$
C_{D} / T m_{D}=\frac{\dot{C}_{D} / T m_{D}-C_{I N} / T m_{D}}{P_{O} / P_{O^{\prime}}},
$$

$C_{I N} / T m_{D}=C_{D} / T m_{D}-\left(C_{D} / T m_{D}-C_{I N} / T m_{D}\right)$, and $F F=C_{I N} / C_{D}$. Values so calculated are shown graphically as the dotted lines in Figures 1, 2 and 4.

\section{MAXIMAL AFFERENT CONSTRICTION AND AFFERENT GLOMERULAR STASIS}

If the glomerular pressure is lowered by constriction of the afferent arterioles, $P_{G}$ will fall below $P_{c}+P_{o}$ and fluid will be aspirated from Bowman's capsule in to the glomerular capillaries, according to equation (1). Interstitial fluid will also be aspirated into the peritubular capillaries, and the hydrostatic pressure in the latter, and therefore the pressure opposing perfusion, will decrease. Insofar as blood escapes into the renal vein, it will aspirate fluid from both Bowman's capsule and interstitial space until the interstitial pressure is reduced from $+15 \mathrm{~mm}$. to $-24 \mathrm{~mm}$. Hg. Actually the glomerular circulation will be arrested intercurrently by viscous resistance, since the apparent viscosity of blood rises very rapidly at critical low rates of flow, a circumstance which itself obstructs perfusion of organs at low hydrostatic pressures (35). This critical increase in viscosity will probably produce glomerular stasis before an increase in afferent resistance per se lowers the glomerular pressure to critical values.

\section{OBSERVED CHANGES IN THE AFFERENT ARTERIOLAR TONE}

It is possible to discover in the present data certain instances where changes in renal blood flow are positively correlated with changes in filtration fraction, but in all these instances the data remain within the statistical parameters which we have accepted as defining the variations in the basal condition, variations possibly attributable to differences in $P_{c}, P_{o}$ and mean systemic pressure in different individuals or in the same individual at different times, and it would be inconsistent with the statistical treatment to attach any contrary significance to them. The most one can say is that slight changes in afferent tone perhaps complicate what is predominantly efferent regulation. If they are to be so interpreted, these changes will be amenable to more accurate evaluation when a method is available for experimentally and reproducibly modifying the tone of the afferent arterioles.

In resume, the observed fact that the rate of glomerular filtration tends to remain constant at varying rates of renal plasma flow must, under the premise of filtration equilibrium, necessarily be the case if the change in rate of renal blood flow is a consequence of changes in the tonus of the efferent arterioles.

The effects of changes in the tone of the afferent arterioles, in the face of constant efferent tone, have been described in principle. However, no method of consistently altering the afferent tone is available at the present time, nor can any of the observed variations in renal blood flow in the present data be definitely attributed to changes in afferent tone.

Returning to a question raised earlier in the discussion, it will be recalled that the calculations on glomerular pressure presented here are made under the premise that filtration pressure equilibrium is attained in the glomeruli. If filtration equilibrium is not attained, the glomerular pressure must exceed $P_{C}+P_{O^{\prime}}$ (equations 10 and 14) by whatever gradient exists between the interior and exterior of the glomerular capillaries, regardless of whether afferent or efferent arteriolar changes predominate in producing the changes in the renal blood flow. It would be expected that this gradient will be roughly proportional to the rate of glomerular filtration, since it represents a head of energy necessary to drive plasma water and solutes through the glomerular membranes, and that it can be closely described by adding some value which is proportional to the filtration rate (for example, $\left.k_{3} C_{I N}\right)$ to the left-hand term of equations $(10)$ and (14). But in the light of all available evidence, and until definite evidence to the contrary is available, we may reasonably consider that at the efferent end of the glomerular capillary this gradient is so small as to be negligible. 
It must be noted that, in view of the relationship shown in Figure 1, neither the filtration rate nor any clearance closely dependent upon it (urea, creatinine, ferrocyanide, etc.) is of any value in revealing changes in renal blood flow in man under such conditions as those examined here.

POSSIBLE RÔLE OF ARTERIOVENOUS ANASTOMOSES

Spanner (29) has reported the existence of anastomoses between the interlobular arterioles and veins in the human kidney, and he believes that these anastomoses permit the retrograde perfusion of the cortical capillaries at a time when the glomerular circulation is partly or wholly arrested. If such anastomoses function as postulated by Spanner, it is conceivable that their dilatation or constriction could increase or decrease the blood flow to the renal tubules, and therefore the diodrast clearance, quite apart from any change in glomerular circulation, under which circumstances the filtration rate might possibly remain constant in spite of large changes in total renal blood flow. The existence of arteriovenous anastomoses cannot be disputed in the face of Spanner's careful injection experiments, but there is no evidence at the present time that they actually do permit the retrograde perfusion of the capillaries in the intact kidney, or that their number is sufficient to increase the total blood flow substantially above that afforded by the glomerular circulation.

Springorum (30), using dogs anesthetized with pernocton, has examined the changes in arterial and renal venous pressure relative to changes in renal blood flow (thermostromuhr) under the action of adrenalin, sympatol, veritol, the carotid sinus reflexes, reflex anuria, and histamine, and has found no evidence of the functional activity of such anastomoses. We would not deny the possible importance of $\mathrm{A}-\mathrm{V}$ anastomoses in shunting blood from arteries to veins under special circumstances, but we are aware of no evidence which indicates that a retrograde perfusion of the capillaries contributes significantly to the changes in blood flow described here. If retrograde perfusion does occur, it would not alter the application of the hemodynamic principles discussed above to the changes in the circulation through the glomeruli. Appropriate correction of the total diodrast clearance for the aglomerular blood flow would increase the value of $F F$, and consequently of $P_{G^{\prime}}$, above the apparent values as now calculated, and insofar as variations in blood flow are purely tubular, would proportionally reduce the amount by which the glomerular blood flow is altered under the various experimental conditions.

The question of whether the number of "active" glomeruli is increased during hyperemia or decreased during ischemia is subordinate to the question of the existence of aglomerular channels permitting the direct perfusion of the tubules, and need not be discussed at this time.

We defer for future discussion the fact that (as judged by the urea clearance) the filtration rate in dogs maintained on low and high protein diets varies directly with renal blood flow (40). It is possible that dietary factors (in contradistinction to those examined here) act primarily upon the afferent arterioles; or it may be that in the dog the afferent arterioles play a larger rôle in the control of renal blood flow than they do in man. It should be noted, however, that the average filtration fraction is considerably higher in the dog (29.7 per cent (4)) than in man (18.9 per cent (8)), whereas the available data on the renal blood flow/cardiac output fraction indicate lower values for this ratio in the dog (18 per cent (13)) than in man $(1.19 / 4.0=29$ per cent $(8))$. If $P_{c}$ and $P_{o}$ are assumed to be the same in the two species, the meager data in the dog indicate that this animal has basally a considerably greater efferent arteriolar tone than has man.

\section{SUMMARY}

Data on the diodrast and inulin clearances (both referred to the tubular excretory mass) obtained under basal conditions and during renal ischemia and hyperemia have been analyzed with special reference to glomerular dynamics.

The concept is developed that the separation of fluid in Bowman's capsule is a process of reversible filtration comparable to the formation of interstitial fluid by the systemic capillaries; and that in the distal portion of the glomerular capillary the hydrostatic pressure and the pressure opposing it, viz., the sum of the plasma oncotic pressure and the capsular (renal interstitial) pressure, are equal. This equality, which 
is designated as filtration equilibrium, will in principle be maintained so long as the glomerular circulation is active and Bowman's capsule contains free fluid.

It is further pointed out that the perfusion of the glomeruli is opposed both by the interstitial (capsular) pressure and by the oncotic pressure of the plasma, the latter remaining effective so long as interstitial fluid exists around the peritubular capillaries and so long as this fluid is in osmotic equilibrium with the plasma at any point.

It is deduced that, where changes in renal blood flow are attributable solely to changes in the tone of the efferent arterioles, the rate of glomerular filtration will be constant and independent of renal blood flow. This is in fact the case under the particular conditions of ischemia and hyperemia examined here.

Taking the plasma oncotic pressure and the capsular pressure at arbitrary values, the equilibrium glomerular pressure is calculated for various conditions of renal blood flow from the diodrast and inulin clearances.

Calculations are presented to show the effects of changes in the tone of the afferent glomerular arterioles on the renal blood flow and the rate of glomerular filtration, but it is pointed out that no method is available at the present time to alter consistently or reproducibly the tone of the afferent arterioles.

The theoretic glomerulo-dynamic factors involved in glomerular stasis, both of efferent and afferent arteriolar origin, and the significance of arteriovenous anastomoses and the retrograde perfusion of the tubules through such anastomoses, are briefly discussed.

\section{BIBLIOGRAPHY}

1. Book, M. H., The secreting area of the glomerulus. J. Anat., 1936, 71, 91.

2. Bunim, J. J., Smith, W. W., and Smith, H. W., The diffusion coefficient of inulin and other substances of interest in renal physiology. J. Biol. Chem., 1937, 118, 667.

3. Chasis, H., Ranges, H. A., Goldring, W., and Smith, H. W., The control of renal blood flow and glomerular filtration in normal man. J. Clin. Invest., 1938, $17,683$.

4. Corcoran, A. C., and Page, I. H., The effects of renin, pitressin, and pitressin and atropine on renal blood flow and clearance. Am. J. Physiol., 1939, 126, 354.
5. Corcoran, A. C., Page, I. H., and Smith, H. W., Renal excretion of diodrast in the dog. Am. J. Physiol., 1940. (In press.)

6. Ekehorn, G., On the principles of renal function. Acta med. Scandinav., 1931, Supp. 36.

7. Forster, R. P., The use of inulin and creatinine as glomerular filtrate measuring substances in the frog. J. Cell. \& Comp. Physiol., 1938, 12, 213.

8. Goldring, W., Chasis, H., Ranges, H. A., and Smith, H. W., Relations of effective renal blood flow and glomerular filtration to tubular excretory mass in normal man. J. Clin. Invest., 1940, 19, 739.

9. Hayman, J. M., Jr., Estimations of affierent arteriole and glomerular capillary pressures in the frog kidney. Am. J. Physiol., 1927, 79, 389.

10. Hendrix, J. P., Westfall, B. B., and Richards, A. N., Quantitative studies of the composition of glomerular urine. XIV. The glomerular excretion of inulin in frogs and necturi. J. Biol. Chem., 1936, 116, 735.

11. Kaplan, B. I., and Smith, H. W., Excretion of inulin, creatinine, xylose and urea in the normal rabbit. Am. J. Physiol., 1935, 113, 354.

12. Landis, E. M., Capillary pressure and capillary permeability. Physiol. Rev., 1934, 14, 404.

13. Levy, S. E., and Blalock, A., Fractionation of the output of the heart and of the oxygen consumption of normal unanesthetized dogs. Am. J. Physiol., 1937, 118, 368.

14. Miller, B. F., Alving, A. S., and Rubin, J., The renal excretion of inulin at low plasma concentrations of this compound, and its relationship to the glomerular filtration rate in normal, nephritic and hypertensive individuals. J. Clin. Invest., 1940, 19, 89.

15. Moritz, A. R., and Hayman, J. M., Jr., The disappearance of glomeruli in chronic kidney disease. Am. J. Path., 1934, 10, 505.

16. Pitts, R. F., The excretion of phenol red by the chicken. J. Cell. \& Comp. Physiol., 1938, 11, 99.

17. Richards, A. N., Croonian lecture; Processes of urine formation. Proc. Roy. Soc., London, s.B, 1938, 126, 398.

18. Richards, A. N., and Walker, A. M., Urine formation in theamphibian kidney. Am. J. M.Sc., 1935, 190, 727.

19. Richards, A. N., Westfall, B. B., and Bott, P. A., Inulin and creatinine clearances in dogs, with notes on some late effects of uranium poisoning. J. Biol. Chem., 1936, 116, 749.

20. Shannon, J. A., The excretion of inulin by the dog. Am. J. Physiol., 1935, 112, 405.

21. Shannon, J. A., The renal excretion of creatinine in man. J. Clin. Invest., 1935, 14, 403.

22. Shannon, J. A., The excretion of inulin and creatinine at low urine flows by the normal dog. Am. J. Physiol., 1936, 114, 362.

23. Shannon, J. A., The excretion of exogenous creatinine by the chicken. J. Cell. \& Comp. Physiol., 1938, $11,123$.

24. Shannon, J. A., and Fisher, S., The renal tubular reabsorption of glucose in the normal dog. Am. J. Physiol., 1938, 122, 765. 
25. Shannon, J. A., and Smith, H. W., The excretion of inulin, xylose and urea by normal and phlorizinized man. J. Clin. Invest., 1935, 14, 393.

26. Smith, H. W., The physiology of the renal circulation. Harvey Lect., 1939-40. (In press.)

27. Smith, H. W., Goldring, W., and Chasis, H., The measurement of the tubular excretory mass, effective blood flow and filtration rate in the normal human kidney. J. Clin. Invest., 1938, 17, 263.

28. Smith, W. W., Finkelstein, N., and Smith, H. W., Renal excretion of the hexitols (sorbitol, mannitol and dulcitol) and their derivatives (sorbitan, isomannide and sorbide) and of endogenous creatininelike chromogen in dog and man. J. Biol. Chem., 1940, 135, 231.

29. Spanner, R., Über Gefässkurzschlüsse in der Niere. Verhandl. d. anat. Gesellsch., 1937, 45, 81.

30. Springorum, P. W., Zur Frage der funktionellen Bedeutung der arteriovenösen Anastomosen für die Niere. Klin. Wchnschr., 1939, 18, 811.

31. Westfall, B. B., and Landis, E. M., The molecular weight of inulin. J. Biol. Chem., 1936, 116, 727.

32. White, H. L., Observations on the nature of glomerular activity, Am. J. Physiol., 1929, 90, 689.

33. White, H. L., Findlay, T., Jr., and Edwards, J. C., Interpretation of diodrast clearances in man. Proc. Soc. Exper. Biol. \& Med., 1940, 43, 11.
34. White, H. L., and Heinbecker, P., Interpretation of diodrast clearances in the dog. Proc. Soc. Exper. Biol. \& Med., 1940, 43, 8.

35. Whittaker, S. R. F., and Winton, F. R., The apparent viscosity of blood flowing in the isolated hindlimb of the dog, and its variation with corpuscular concentration. J. Physiol., 1933, 78, 339.

36. Wies, C. H., and Peters, J. P., The osmotic pressure of proteins in whole serum. J. Clin. Invest., 1937, 16, 93.

37. Winton, F. R., The control of the glomerular pressure by vascular changes within the isolated mammalian kidney, demonstrated by the actions of adrenaline. J. Physiol., 1931, 73, 151.

38. Winton, F. R., Physical factors involved in the activities of the mammalian kidney. Physiol. Rev., $1937,17,408$.

39. Van Slyke, D. D., Hiller, A., and Miller, B. F., The distribution of ferrocyanide, inulin, creatinine, and urea in the blood and its effect on the significance of their extraction percentages. Am. J. Physiol., 1935, 113, 629.

40. Van Slyke, D. D., Rhoads, C. P., Hiller, A., and Alving, A. S., The relationship of the urea clearance to the renal blood flow. Am. J. Physiol., 1934, 110, 387. 